\title{
Low hemoglobin levels are associated with upper gastrointestinal bleeding
}

\author{
MINORU TOMIZAWA ${ }^{1}$, FUMINOBU SHINOZAKI ${ }^{2}$, RUMIKO HASEGAWA ${ }^{3}$, YOSHINORI SHIRAI ${ }^{3}$, \\ YASUFUMI MOTOYOSHI ${ }^{4}$, TAKAO SUGIYAMA ${ }^{5}$, SHIGENORI YAMAMOTO ${ }^{6}$ and NAOKI ISHIGE ${ }^{7}$ \\ Departments of ${ }^{1}$ Gastroenterology, ${ }^{2}$ Radiology, ${ }^{3}$ Surgery, ${ }^{4}$ Neurology, ${ }^{5}$ Rheumatology, ${ }^{6}$ Pediatrics and \\ ${ }^{7}$ Neurosurgery, National Hospital Organization Shimoshizu Hospital, Yotsukaido, Chiba 284-0003, Japan
}

Received May 20, 2016; Accepted July 17, 2016

DOI: 10.3892/br.2016.727

\begin{abstract}
Upper gastrointestinal (GI) bleeding can be fatal. Blood test variables were reviewed in search of threshold values to detect the presence of occult upper GI bleeding. The records of 1,023 patients who underwent endoscopy at the National Hospital Organization Shimoshizu Hospital from October 2014, to September 2015, were retrospectively reviewed. Of those, 95 had upper GI bleeding. One-way analysis of variance was applied to blood test variables comparing patients with and without upper GI bleeding. Logistic regression analysis was applied to detect the association of blood test parameters with upper GI bleeding, and receiver-operator characteristics were applied to establish threshold values. White blood cell count (WBC), platelet (Plt) count, and blood urea nitrogen (BUN) levels were higher, and hemoglobin $(\mathrm{Hb})$ and albumin (Alb) levels were lower in patients with upper GI bleeding. Logistic regression analysis showed that low $\mathrm{Hb}$ was significantly associated with upper GI bleeding and a $\mathrm{Hb}$ value of $10.8 \mathrm{~g} / \mathrm{dl}$ was established as the threshold for the diagnosis. In patients with upper GI bleeding, WBC, Plt count, and BUN levels were higher and $\mathrm{Hb}$ and $\mathrm{Alb}$ levels were reduced. $\mathrm{Hb}$ at $10.8 \mathrm{~g} / \mathrm{dl}$ was established as a threshold value to detect upper GI bleeding.
\end{abstract}

\section{Introduction}

Upper gastrointestinal (GI) bleeding is defined as mucosal bleeding from the proximal portion of the esophagus to the ligament of Treitz. Upper GI bleeding is caused by gastric ulcers, duodenal ulcers, and gastric cancer (1) and can be fatal,

Correspondence to: Dr Minoru Tomizawa, Department of Gastroenterology, National Hospital Organization Shimoshizu Hospital, 934-5 Shikawatashi, Yotsukaido, Chiba 284-0003, Japan E-mail: nihminor-cib@umin.ac.jp

Key words: hemoglobin, receiver-operator characteristics, blood urea nitrogen, albumin, upper gastrointestinal bleeding with a mortality rate of $3.5-7.4 \%(2,3)$. Currently, patients with upper GI bleeding are diagnosed and treated with endoscopy (4), and embolization with angiography is performed on refractory patients $(5,6)$. When patients develop hemodynamic instability, the mortality rate rises to $40 \%$ (7). It is pivotal that patients with upper GI bleeding are identified and treated promptly to avoid hemodynamic crisis.

Identification of upper GI bleeding is essential to its management. Glasgow Batchford Scores, Modified Early Waning Score, and pre-endoscopic Rockall scores contribute to the stratification of patients at risk for hemodynamic crisis, the need for transfusion, and hospitalization (8). However, scoring systems can fail to detect patients who are hemodynamically stable despite upper GI bleeding. Not only is it important to identify acute bleeding, but also to identify bleeding caused by gastric cancer and other less acute conditions that require intervention. Blood tests are non-invasive, rapid and inexpensive and offer a group of parameters in which thresholds might suggest the presence of occult but significant upper GI bleeding.

Thus, the aim of the present study was to establish threshold values of screening blood tests to detect upper GI bleeding. A retrospective investigation was conducted to compare blood test variables between patients with or without upper GI bleeding.

\section{Materials and methods}

Patients. Patients were selected from all of those who had endoscopy at the National Hospital Organization Shimoshizu Hospital, Yotsukaido, Chiba, Japan from October 2014, to September 2015. Endoscopy was performed in 1,023 patients, 431 men (mean age 68.1 \pm 12.9 years), and 592 women (66.4 \pm 12.3 years). Indications for endoscopy included anemia, abdominal pain, and melena but also included some screening procedures. The present study was approved by the National Hospital Organization Shimoshizu Hospital Ethics Committee. Since the procedures were performed as part of our routine clinical care, written informed consent for inclusion in the study was waived. Patient records were depersonalized and retrospectively analyzed. Written informed consent was obtained for the endoscopy from all the patients. 
Table I. Number of patients with upper gastrointestinal bleeding.

\begin{tabular}{lc}
\hline Type & Patients (no.) \\
\hline Gastric ulcer & 58 \\
Gastric cancer & 9 \\
Hemorrhagic gastritis & 9 \\
Reflux esophagitis & 7 \\
Duodenal ulcer & 8 \\
Acute gastric mucosal lesion & 2 \\
Esophageal varix & 2 \\
Total & 95 \\
\hline
\end{tabular}

Table II. Comparison of blood test variables between patients with or without upper gastrointestinal bleeding.

\begin{tabular}{|c|c|c|c|c|}
\hline \multirow[b]{2}{*}{ Variables } & \multirow[b]{2}{*}{ Normal range } & \multicolumn{2}{|c|}{$\begin{array}{l}\text { Upper gastrointestinal } \\
\text { bleeding }(\text { mean } \pm S D)\end{array}$} & \multirow[b]{2}{*}{ P-value } \\
\hline & & Absent & Present & \\
\hline Age, years & & $69.3 \pm 13.9$ & $69.3 \pm 12.9$ & 0.983 \\
\hline Gender, m/f & & $459 / 812$ & $53 / 42$ & \\
\hline $\mathrm{WBC}, 10^{3} / \mu 1$ & $3.5-8.5$ & $6.6 \pm 2.2$ & $8.4 \pm 6.2$ & 0.020 \\
\hline $\mathrm{Hb}, \mathrm{g} / \mathrm{dl}$ & $13.5-17.0$ & $12.8 \pm 2.0$ & $9.7 \pm 3.1$ & $<0.001$ \\
\hline Plt, $10^{4} / \mu 1$ & $15.0-35.0$ & $23.9 \pm 6.7$ & $30.0 \pm 15.9$ & 0.005 \\
\hline CRP, mg/dl & $0.0-0.3$ & $1.0 \pm 2.5$ & $2.4 \pm 3.8$ & 0.074 \\
\hline $\mathrm{TP}, \mathrm{g} / \mathrm{dl}$ & $6.7-8.3$ & $6.8 \pm 0.6$ & $8.0 \pm 9.6$ & 0.298 \\
\hline $\mathrm{Alb}, \mathrm{g} / \mathrm{dl}$ & $3.9-4.9$ & $3.9 \pm 0.8$ & $3.3 \pm 1.0$ & 0.005 \\
\hline ALP, IU/1 & $115-359$ & $267 \pm 263$ & $275 \pm 191$ & 0.899 \\
\hline AST, IU/1 & $13-33$ & $27 \pm 32$ & $140 \pm 585$ & 0.083 \\
\hline ALT, IU/1 & $8-42$ & $23 \pm 25$ & $122 \pm 516$ & 0.089 \\
\hline$\gamma$-GTP, IU/1 & $10-47$ & $51.4 \pm 89.8$ & $108 \pm 261$ & 0.213 \\
\hline LDH, IU/1 & $119-229$ & $209 \pm 83$ & $243 \pm 172$ & 0.242 \\
\hline $\mathrm{UA}, \mathrm{mg} / \mathrm{dl}$ & $2.3-7.0$ & $5.17 \pm 1.52$ & $4.46 \pm 1.59$ & 0.090 \\
\hline BUN, mg/dl & $8.0-22.0$ & $14.7 \pm 5.0$ & $18.8 \pm 12.9$ & 0.043 \\
\hline Cre, mg/dl & $0.40-0.70$ & $1.78 \pm 2.02$ & $0.77 \pm 0.26$ & 0.490 \\
\hline $\mathrm{TG}, \mathrm{mg} / \mathrm{dl}$ & $30-150$ & $115 \pm 62$ & $91 \pm 27$ & 0.163 \\
\hline HDL, mg/dl & $49-75$ & $62.5 \pm 18.9$ & $56.7 \pm 26.7$ & 0.392 \\
\hline LDL (mg/dl & $0-139$ & $112 \pm 29$ & $99 \pm 48$ & 0.214 \\
\hline $\mathrm{BG}, \mathrm{mg} / \mathrm{dl}$ & $69-104$ & $111 \pm 52$ & $118 \pm 35$ & 0.669 \\
\hline $\mathrm{HbA} 1 \mathrm{c}, \%$ & $4.7-6.2$ & $5.8 \pm 0.7$ & $7.1 \pm 3.5$ & 0.107 \\
\hline
\end{tabular}

$\mathrm{SD}$, standard deviation; $\mathrm{m}$, male; f, female; WBC, white blood cell count; $\mathrm{Hb}$, hemoglobin; Plt, platelet; CRP, C-reactive protein; TP, total protein; Alb, albumin; ALP, alkaline phosphatase; AST, aspartate aminotransferase; ALT, alanine aminotransferase; $\gamma$-GTP, $\gamma$-glutamyl transpeptidase; LDH, lactate dehydrogenase; UA, uric acid; BUN, blood urea nitrogen; Cre, creatinine; TG, triglyceride; HDL, high-density lipoprotein cholesterol; LDL, low-density lipoprotein cholesterol; BG, blood glucose; HbA1c, hemoglobin A1c.

Endoscopy. The endoscopes used included Olympus models GIF-N260H, GIF-XP260NS, GIF-PG260, GIF-XQ260, and GIF-Q260 (Olympus Corp., Tokyo, Japan). Bleeding from a
Table III. Results of logistic regression analysis.

\begin{tabular}{lccc}
\hline Variables & Odds ratio & $95 \% \mathrm{CI}$ & P-value \\
\hline $\mathrm{WBC}$ & 2.67 & $0.000-3350$ & 0.801 \\
$\mathrm{Hb}$ & 49.5 & $1.007-6229$ & 0.049 \\
$\mathrm{Plt}$ & 0.212 & $0.0032-9.592$ & 0.432 \\
$\mathrm{Alb}$ & 2.26 & $0.535-122.4$ & 0.670 \\
$\mathrm{BUN}$ & 0.118 & $0.000-16.12$ & 0.420 \\
\hline
\end{tabular}

CI, confidence interval; WBC, white blood cell count; Hb, hemoglobin; Plt, platelet; Alb, albumin; BUN, blood urea nitrogen.

Table IV. Discriminatory threshold value for $\mathrm{Hb}$.

\begin{tabular}{lcccc}
\hline Variable & $\begin{array}{c}\text { Area under } \\
\text { curve }\end{array}$ & $\begin{array}{c}\text { Threshold } \\
\text { value }(\mathrm{g} / \mathrm{dl})\end{array}$ & $\begin{array}{c}\text { Sensitivity } \\
(\%)\end{array}$ & $\begin{array}{c}\text { Specificity } \\
(\%)\end{array}$ \\
\hline $\mathrm{Hb}$ & 0.7867 & 10.8 & 62.5 & 91.6 \\
\hline
\end{tabular}

$\mathrm{Hb}$, hemoglobin.

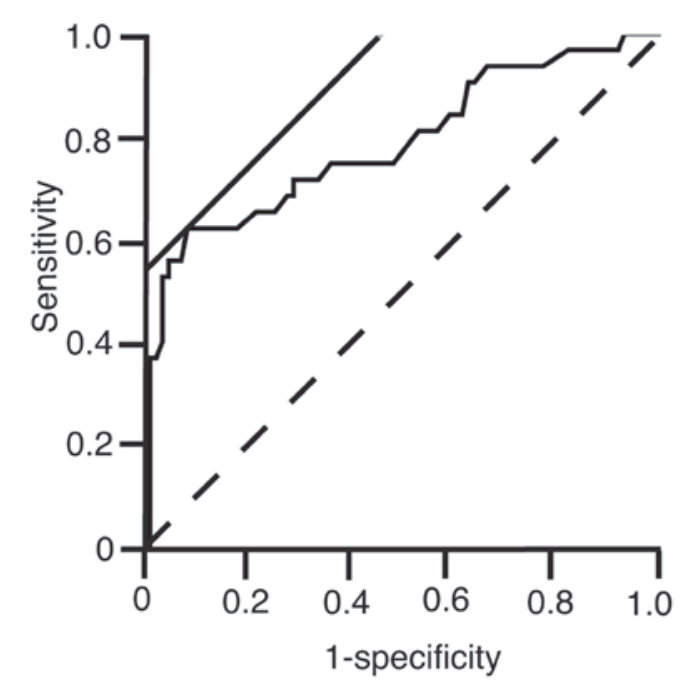

Figure 1. Receiver-operator characteristics analysis. Receiver-operator characteristics analysis was performed in search of a threshold value for the identification of upper gastrointestinal bleeding. Solid straight line, a line with a slope of $45^{\circ}$ to calculate threshold using JMP 10.0.2 software; broken line, reference.

gastric or duodenal ulcer was classified as a spurting vessel (1a), an oozing vessel (1b), a visible vessel (2a), or a clot (2b), according to the Forrest classification system (9). Table I shows the diagnosis of patients.

Blood test variables. Screening blood tests included white blood cell count (WBC), hemoglobin ( $\mathrm{Hb}$ ), platelet (Plt), C-reactive protein (CRP), total protein, albumin (Alb), alkaline phosphatase, aspartate aminotransferase, alanine aminotransferase (ALT), $\gamma$-glutamyl transpeptidase, lactate dehydrogenase, uric acid, blood urea nitrogen (BUN), creatinine (Cre), triglycerides, high-density lipoprotein cholesterol, 
low-density lipoprotein cholesterol, blood glucose, and $\mathrm{HbA1c}$

Statistical analysis. One-way analysis of variance was applied to identify an association between blood test variables and the presence of upper GI bleeding. Logistic regression analysis was then used to correlate values linked to upper GI bleeding. Receiver-operator characteristics analysis was finally applied to establish threshold values. JMP software, version 10.0.2 (SAS Institute, Cary, NC, USA) was used for statistical analysis.

\section{Results}

To identify blood test variables associated with upper GI bleeding, one-way analysis of variance was performed. WBC $(\mathrm{P}=0.02)$, $\mathrm{Plt}(\mathrm{P}=0.005)$, and $\mathrm{BUN}(\mathrm{P}=0.04)$ were elevated and $\mathrm{Hb}(\mathrm{P}<0.001)$ and $\mathrm{Alb}(\mathrm{P}=0.005)$ were reduced in patients with upper GI bleeding (Table II).

Logistic regression analysis was performed to reveal blood test variables associated with upper GI bleeding (Table III). $\mathrm{Hb}$ had a significant association with upper GI bleeding $(\mathrm{P}=0.049)$ with an odds ratio of 45.9 (95\% confidence interval, 0.007-6.229).

Since these results indicated that $\mathrm{Hb}$ might be a strong discriminatory parameter, receiver-operator characteristics were utilized to establish a threshold value for the existence of upper GI bleeding (Fig. 1). The area under the curve was 0.7867 and the threshold value calculated was $10.8 \mathrm{~g} / \mathrm{dl}$, with a sensitivity of $62.5 \%$ and specificity of $91.6 \%$ (Table IV).

\section{Discussion}

Blood test variables are easy to evaluate. Hoffmann et al (10) investigated a number of blood test variables and demonstrated that changes in WBC, Hb, Plt, CRP, ALT, and Cre levels are associated with upper GI bleeding. In the present study, WBC, Plt, and BUN were elevated, and $\mathrm{Hb}$ and $\mathrm{Alb}$ were reduced in patients with upper GI bleeding. Elevated BUN and low Alb have not been reported previously. BUN is known to be produced through protein metabolism $(11,12)$. Blood in the GI tract is digested to protein, and is eventually metabolized to urea $(13,14)$. It is therefore reasonable to conclude that BUN was elevated in patients with upper GI bleeding. Higher BUN levels indicate more severe upper GI bleeding (15), and elevated BUN can also discriminate upper from lower GI bleeding (16). Furthermore, Alb is a marker of nutritional state (17) and can reflect a severe state of upper GI bleeding (18). The results of the present study were consistent with these observations.

Upper GI bleeding is sometimes fatal, and the European Society of Gastrointestinal Endoscopy recommends maintaining $\mathrm{Hb}$ levels between 7.0-9.0 g/dl using blood transfusion in order to reduce mortality (19). In the present study, the threshold value calculated to select patients at risk for ongoing upper GI bleeding was $10.8 \mathrm{~g} / \mathrm{dl}$. Previously we calculated the threshold value of $\mathrm{Hb}$ to be $11.7 \mathrm{~g} / \mathrm{dl}$. Our threshold values were higher than the recommendation (19). It is possible the present study included patients with mild upper GI bleeding. Dahlerup et al (20) reported that mild upper GI bleeding includes patients with malignancy. Patients should be subjected to endoscopy before they develop hemodynamic instability, and those who are hemodynamically stable but with a $\mathrm{Hb}<10.8 \mathrm{~g} / \mathrm{dl}$ may be recommended for endoscopy, since diagnosis would improve management and treatment would reduce the risk of further or delayed bleeding. One limitation of the present study was that it was based on a small number of patients with upper GI bleeding. Future studies with a greater number of recruited patients should be undertaken.

In conclusion, $\mathrm{WBC}, \mathrm{Plt}$, and BUN were elevated and $\mathrm{Hb}$ and Alb were lower in patients with upper GI bleeding. We established that a threshold value of $10.8 \mathrm{~g} / \mathrm{dl}$ of $\mathrm{Hb}$ suggests the presence of upper GI bleeding and identifies patients at risk for hemodynamic crisis.

\section{References}

1. Theocharis GJ, Thomopoulos KC, Sakellaropoulos G, Katsakoulis E and Nikolopoulou V: Changing trends in the epidemiology and clinical outcome of acute upper gastrointestinal bleeding in a defined geographical area in Greece. J Clin Gastroenterol 42: 128-133, 2008.

2. Hearnshaw SA, Logan RF, Lowe D, Travis SP, Murphy MF and Palmer KR: Acute upper gastrointestinal bleeding in the UK: Patient characteristics, diagnoses and outcomes in the 2007 UK audit. Gut 60: 1327-1335, 2011.

3. Leontiadis GI, Molloy-Bland M, Moayyedi P and Howden CW: Effect of comorbidity on mortality in patients with peptic ulcer bleeding: Systematic review and meta-analysis. Am J Gastroenterol 108: 331-345, quiz 346, 2013.

4. Kim SY, Hyun JJ, Jung SW and Lee SW: Management of non-variceal upper gastrointestinal bleeding. Clin Endosc 45: 220-223, 2012.

5. Wilkins T, Khan N, Nabh A and Schade RR: Diagnosis and management of upper gastrointestinal bleeding. Am Fam Physician 85: 469-476, 2012.

6. Katano T, Mizoshita T, Senoo K, Sobue S, Takada H, Sakamoto T, Mochiduki H, Ozeki T, Kato A, Matsunami K, et al: The efficacy of transcatheter arterial embolization as the first-choice treatment after failure of endoscopic hemostasis and endoscopic treatment resistance factors. Dig Endosc 24: 364-369, 2012.

7. Walsh RM, Anain P, Geisinger M, Vogt D, Mayes J, Grundfest-Broniatowski S and Henderson JM: Role of angiography and embolization for massive gastroduodenal hemorrhage. J Gastrointest Surg 3: 61-65, discussion 66, 1999.

8. Bozkurt S, Köse A, Arslan ED, Erdoğan S, Üçbilek E, Çevik İ, Ayrık C and Sezgin O: Validity of modified early warning, Glasgow Blatchford, and pre-endoscopic Rockall scores in predicting prognosis of patients presenting to emergency department with upper gastrointestinal bleeding. Scand J Trauma Resusc Emerg Med 23: 109, 2015.

9. Forrest JA, Finlayson ND and Shearman DJ: Endoscopy in gastrointestinal bleeding. Lancet 2: 394-397, 1974.

10. Hoffmann V, Neubauer H, Heinzler J, Smarczyk A, Hellmich M, Bowe A, Kuetting F, Demir M, Pelc A, Schulte S, et al: A novel easy-to-use prediction scheme for upper gastrointestinal bleeding: Cologne-WATCH (C-WATCH) risk score. Medicine (Baltimore) 94: e1614, 2015.

11. Schutz Y: Protein turnover, ureagenesis and gluconeogenesis. Int J Vitam Nutr Res 81: 101-107, 2011.

12. Adeva MM, Souto G, Blanco N and Donapetry C: Ammonium metabolism in humans. Metabolism 61: 1495-1511, 2012.

13. Mardini $\mathrm{H}$ and Record C: Pathogenesis of hepatic encephalopathy: Lessons from nitrogen challenges in man. Metab Brain Dis 28: 201-207, 2013

14. Häberle J: Clinical and biochemical aspects of primary and secondary hyperammonemic disorders. Arch Biochem Biophys 536: 101-108, 2013.

15. Tomizawa M, Shinozaki F, Hasegawa R, Shirai Y, Motoyoshi Y, Sugiyama T, Yamamoto S and Ishige N: Patient characteristics with high or low blood urea nitrogen in upper gastrointestinal bleeding. World J Gastroenterol 21: 7500-7505, 2015.

16. Tomizawa M, Shinozaki F, Hasegawa R, Shirai Y, Motoyoshi Y, Sugiyama T, Yamamoto $\mathrm{S}$ and Ishige N: Laboratory test variables useful for distinguishing upper from lower gastrointestinal bleeding. World J Gastroenterol 21: 6246-6251, 2015. 
17. Lee JL, Oh ES, Lee RW and Finucane TE: Serum albumin and prealbumin in calorically restricted, nondiseased individuals: A systematic review. Am J Med 128: 1023.e1-22, 2015.

18. Tung CF, Chow WK, Chang CS, Peng YC and $\mathrm{Hu}$ WH: The prevalence and significance of hypoalbuminemia in non-variceal upper gastrointestinal bleeding. Hepatogastroenterology 54: 1153-1156, 2007.

19. Gralnek IM, Dumonceau JM, Kuipers EJ, Lanas A, Sanders DS, Kurien M, Rotondano G,Hucl T, Dinis-Ribeiro M, Marmo R, et al: Diagnosis and management of nonvariceal upper gastrointestinal hemorrhage: European Society of Gastrointestinal Endoscopy (ESGE) Guideline. Endoscopy 47: a1-a46, 2015.
20. Dahlerup JF, Eivindson M, Jacobsen BA, Jensen NM, Jørgensen SP, Laursen SB, Rasmussen $M$ and Nathan T: Diagnosis and treatment of unexplained anemia with iron deficiency without overt bleeding. Dan Med J 62: C5072, 2015. 